\title{
TIEMPO DE DESTRUCCIÓN: ¿NOVELA ESTRUCTURAL?
}

Por

JOSÉ SCHRAIBMAN

Washington University

En Novela española de nuestro tiempo Gonzalo Sobejano distingue tres grupos de novela: 1 . novela existencial; 2 . novela social; y 3 . novela estructural. Esta última tiene como características principales dar relieve a la forma o a la estructura formal, la indagación de la estructura o conciencia personal, y la exploración de la estructura del complejo social. ${ }^{1}$ A sus lúcidas palabras sobre Tiempo de silencio, y a su artículo en que examina Tiempo de destrucción-llegado a nuestras manos por él-quisiéramos añadir estas reflexiones sobre Tiempo de destrucción, unas reflexiones usando la definición de novela estructural articulada más arriba. ${ }^{2}$

En cuanto al concepto "forma" conviene citar la voz del narrador mismo en Tiempo de destrucción: " "la vida humana está de tal modo trabada que cualquier escena o situación remite a su totalidad..."(p. 221). Aún siendo novela póstuma e incompleta casi pudiera alegarse que si se lee la novela alterando el orden de cada parte, o cada capítulo, su efecto y sus relaciones siguen dándose igual para el lector. La novela, en cuanto estructura, se

\footnotetext{
I Véase el capítulo XIII de la segunda edición de Novela española de nuestro tiempo (Madrid: Prensa Española, 1975).

2 Gonzalo Sobejano, "Conciencia crítica en la novela española nueva", Lección inaugural del curso académico del año 1977 en el Centro Asociado de la Universidad Nacional de Educación a Distancia en Pontevedra. Por no ser de fácil adquisición doy una idea general de este excelente ensayo. Sobejano define la novela como "conciencia", como "con-saber", o "saber con". Tras unas páginas sintéticas sobre la novela contemporánea, y su lectura, Sobejano pasa a un análisis muy certero de Tiempo de destrucción y Juan sin Tierra (1975) de Juan Goytisolo. Sobejano defiende muy bien su tesis de que Tiempo de destrucción es verdaderamente un Bildungsroman, explica muy bien la relación entre el padre, Demetrios, y el hijo, Agustín, y la liberación sexual y ética de éste. Sobeja no subraya lo novedoso de esta "Comprensión de la realidad social y personal en una liberación en lo espontáneo o glorificación del Eros". Pasa entonces a una explicación de Juan sin Tierra, también como búsqueda de la clarividencia, como conciencia crítica y destrucción de mitos, incluidos los del cuerpo y sus excrecencias, y el lenguaje.

3 Todas las citas de la novela son de la edición de José Carlos Mainer (Barcelona: Seix Barral, 1975), y se refieren a las páginas de esta edición.
} 
desarrolla a nivel psicológico como la búsqueda (indagación) de la autenticidad (conciencia personal) de Agustín a través de su realización sexual y social. El hombre indaga sobre su propio ser en relación con los demás, con los mitos que tiene en común con ellos, con el lenguaje. Y, en cuanto al análisis de la estructura social, Martín-Santos vuelve a usar, como en Tiempo de silencio, como metáfora del nexo social, a la ciudad: "la vieja ciudad tiene su río convertido en cloaca" (p. 301). Se establece así una metáfora "río-cloaca", cuyo desarrollo nos permite descubrir las relaciones existentes entre sus habitantes, hombre-crustáceos en putrefacción, el ambiente, río-cloaca, y las fuerzas ideológicas de putrefacción que determinan estas relaciones. Esta metáfora estructura todos los niveles de la obra, el de la conciencia personal: el hombre-crustáceo; el del contexto social: la ciudad, con su río-cloaca; y el de la superestructura novelística, o del lenguaje, que determina en realidad el tex to entero.

Si bien el interés de Martín-Santos es desentrañar el significado de la vida, su método es la analítica existencial aplicada a la psiquiatría y a la presentación de Agustín. La justificación la da ya en el prólogo: “...En efecto, ¿Qué se le da al lector? ¿El destino de un hombre individual? ¿No son acaso las peripecias íntimas... en el fondo, solamente anécdotas? No. Yo he llegado a pensar que más que anécdotas eran parábolas. Surgen, a veces, hombres parabólicos y la humanidad se nutre de tales paraboloides y bucea en su simbolismo durante siglos...". ${ }_{4}^{4}$

De modo que el personaje constituye un ejemplo paraboloide por medio del cual el novelista psiquiatra puede, por extrapolación, estudiar, conocer y mostrar las "peripecias íntimas" de los hombres. El método de estudio parte de la analítica existencial de Heidegger. Faltaría añadir que el paso previo al análisis es el fenomenológico. Es preciso describir fenomenológicamente la situación del hombre en el mundo, el Dasein: "ser-ahí tiene su propia mundanidad". 5

Esta descripción la realiza el autor utilizando la técnica (no el método) objetivista: "La anécdota-parábola, que acaba de ser relatada siguiendo la técnica objetivista, más que nada sirve para hacer patentes las insuficiencias de dicha técnica... No deja de ser estéticamente útil esta seudonecesidad. Ante todo porque corresponde a una realidad psicológica profunda que en nuestros propios actos ignoramos" (p. 255).

\footnotetext{
${ }^{4}$ La cita es del "Prólogo a Tiempo de destrucción", en Luis Martín Santos, Apólogos (Barcelona: Seix Barral, 1970), p. 149. Estas páginas de Martín Santos no tienen pérdida, y debieran leerse con cuidado, en especial sus reflexiones sobre el hado, sus páginas dedicadas al lector, al vampirolector, y su burla de los clisés de la narración.
}

5 "La psiquiatría existencial", en Apólogos, p. 135. 
Esta realidad psicológica profunda es la que puede llegar a conocerse por medio de la analítica existencial. Hay que conocer al hombre, un ser-ahí identificado en un quién: Agustín, en sus modos de ser en-sí-mismo o ser-uno y con "las pecularidades del ser-con" o de relacionarse con los demás. ${ }^{6}$ Para llegar a ese conocimiento es fundamental en la novela el modo de encontrarse con el otro, especialmente a través de la relación sexual de Agustín con la mujer. Lo explica el autor cuando dice: "El descubrimiento de la verdad de uno mismo mediante la sorpresa es el descubrimiento de la realización de un destino que no había sido previsto ni buscado." Ese es pues el significado del encuentro sexual fallido de Agustín. Este corresponde al tercer elemento con que trabaja la analítica existencial: "un ser-ahí con sus existenciarios fundamentales del comprender, el encontrarse, el habla y la caída". ${ }^{7}$ Es en la caída cuand o el hombre salta a la vista, sorprendiénd ole la plenitud de su ser, y la pregunta por si mismo. Es el asombro que produce la caída, lo que posibilita la reflexión, la toma de distancia del ser-en-sí con respecto al ser-para-sí y para-el-otro, en su mundanidad. Esta mundanidad significaba para Agustín "la coincidencia ex traordinaria de todos los preceptos religiosos y de todos los mandamientos de la higiene y prudencia vital acerca de lo que yo no debía hacer..." (p. 48). Es por esa razón por la cual después de pasarse mucho tiempo pensando, toma su decisión "desde dentro de todas las prohibiciones con que había sido abrumado desde una niñez confusa" (p. 48) de investigar, saber "si era pecado o no era pecado"(p. 49).

$\mathrm{Y}$ a la vez buscar por un nuevo camino "la confirmación de su (mi) pertenencia al mundo de los otros"'(p. 47). Y esta pertenencia al mundo de los otros se manifiesta en la novela a través de las vicisitudes de Agustín. El desarrollo biográfico de la novela nos muestra a Agustín sucesivamente en el seno de la familia, la escuela, el seminario, la universidad, la escuela de leyes, $y$, una vez graduado en la vida, requerido del mundo en su mundanidad en cuanto juez, para la investigación de un crimen. Esto da lugar al análisis de la especialidad en la que se da el ser-ahí de todos los hombres contemporáneos y co-espaciales y co-temporales de Agustín.

Martín-Santos usa una técnica objetivista e impresionista a la vez para presentar la familia y el trayecto vital recorrido por Agustín. El autornarrador no sólo describe lo que ocurre a nivel de trama, sino que destruye lo que significa la entidad descrita mediante el uso del lenguaje hiperbólico. Por ejemplo, el lenguaje rimbombante utilizado en esta descripción, constituye

\footnotetext{
${ }^{6}$ Apólogos, p. 134.

7 Apólogos, p. 134. Para una lectura "existencialista", véase, Gemma Roberts, "Conflicto entre razón y vida en Tiempo de destrucción", en Insula. Nos. 396-397 (noviembre-diciembre de 1979), pp. 10-11.
} 
una parodia de la exagerada significación que posee la universidad por sí misma. El autor lla ma a Salamanca "la ciudad de las doradas piedras", "la casi Roma-eterna cuyo vientre hinchen numerosas catedrales, que enhechiza los espíritus de cuantos la conocen y cuyo corazón batiente es una plaza giroscópica a despecho de su cuadrangular figura, con orgiásticos dispositivos luminosos las noches de septiembre y con rígida discriminación de sexos deambulantes" (p. 85).

Es en este punto donde se produce otra caída, esta vez la caída del lenguaje, la cual involucra no sólo a los personajes de la obra, especialmente a Demetrios y a Agustín, sino al autor-narrador y a nosotros como lectores. Los existenciarios fundamentales del ser-ahí son: el comprender, el encontrarse, el habla y la caída, en que la única forma posible del encontrarse es el habla. La sexualidad de Agustín ha fallado en este intento de encuentro con el otro, ha producido una primera caída, un primer distanciamiento sorpresivo. El segundo distanciamiento será producido por la caída del lenguaje: el ser-a-la-mano.

Demetrios se da cuenta de que al participar del "más puro acento castellano" (p. 134) participa a su vez de los valores de la más pura cultura castellana; pero llevado por los ardores de sus años mozos comienza a aceptar no sólo las caderas de las mujeres catalanas, sino a pensar que tal vez su acento catalán comunique "algo" que "el más puro acento castellano" no logra comunicar. Su caída constituye no sólo un pecado de la carne, sino también un "pecado filológico" (p. 135). Esta caída constituye para Demetrios una apertura hacia el conocimiento de su ser-ahí y de su ser-con-y-para-el-otro. La aceptación de una comunicación en el dialecto catalán lo lleva a descubrir las posibilidades libertarias del anarco-sindicalismo, que le son transmitidas por un mendigo con el cual pasa la noche (pp. 141-142). Pero Demetrios está toda vía cogido por el "defensor del orden constituido", se enfrenta a esa nueva especialidad como sintiéndola ajena, la objetiviza por medio del sueño y "sintiendo que estaba rompiendo el vínculo", se evade de la posibilidad de esa ruptura: "Demetrios a la luz del sol no se sintió en pecado y, viendo cuán feo era el limpiabotas... se fue hacia la estación desvinculándose de su ser-parael-otro por una pura cuestión de estética" (p. 145).

Sin embargo el autor puede todavía rescatar para Agustín, hijo de Demetrios, la posibilidad del asombro después de la caída, en la ruptura. Demetrios mira hacia el pasado, está cogido y no puede desvincularse: Agustín todavía posee esa oportunidad. Su especialidad está presentada gracias a que el novelista "puede adivinar. . . la escena clave, coronada de todo el devenir vital de su héroe, y gracias a esta elección, su narración posterior alcanza su ritmo interno y su desarrollo armónico; o más bien ocurre que la vida humana está de tal modo trabada, que cualquier escena o situación 
remite a su totalidad" (p. 221). Al mismo tiempo, el novelista deberá proporcionar las claves para la demostración de lo que necesita decir.

En la novela, nos parece haber descubierto tres claves fundamentales para la interpretación de la obra. Las tres son elaboraciones lingüísticas, o metáforas: la de la ciudad, la de la fiesta y la del lenguaje mismo.

Agustín vive en la ciudad donde el río se ha convertido en cloaca. Sus habitantes son peces, crustáceos en descomposición. Éste es el estado al cual han llegado los hombres habitantes de la vieja ciudad. El narrador, espectador de este entorno, "arrisca la nariz" al observar esta realidad. Toma distancia y se transforma en juez. El narrador-juez-Agustín-en su primer enfrentamiento intenta, ya lo había hecho Demetrios, resistirse, y opinar que "el espectáculo carece de valor simbólico (metafórico) y que no se refiere sino indirectamente a la sociedad que lo produce" (p. 302), pero en cuanto juez, debe penetrar en la cloaca y descubrir allí que las apariencias de la descomposición revelan engañosamente la vida de los sujetos con los cuales su trabajo le pone en contacto. El juez, intruso, no encontrará otra vía que penetrar en el seno de esa sociedad, despojado de su máscara: "por eso, cuando, vestido de oscuro, sin antifaz alguno, con su andar de esquina lateralizado, se atrevió a subir por la vieja escalera... sintió un primer regusto de repugnancia" (p. 314). Allí, encontró al pueblo vestido de carnaval, con máscaras. Las máscaras del carnaval, constituyen una manifestación de un proceso de unificación artificial en el que participan los habitantes de la ciudad. Esta unificación o uniformación del vestuario, de los gestos, de los deseos, del lenguaje, lleva a una unificación artificial de la categoría social. Es el significado último de la fiesta. Por ella, el hombre ibérico se olvida de su condición y participa del contento general, se ofrece como espectáculo al tiempo que contempla el espectáculo que otros ofrecen de sí mismos, riéndose en este "ofrecerse-contemplarse" (p. 310) a la colectividad, para que otros devoren "ese respeto que yo, el primero, deliberadamente sacrifico" (p. 310).

La participación en el ambiente carnavalesco, despierta en Agustín la concupiscencia; concupiscencia del saber, el deseo de descubrir por sí mismo el misterio de la vida que a su vez le revelará el misterio de sí mismo. De esta manera el encuentro con el otro le servirá para la realización de su propio ser-ahí-con-el-otro: "Tras su primera aproximación a los datos... Agustín (juez), creyó discernir con certeza totalmente infundada la verdad. No sólo la verdad de los hechos...sino también otra verdad más compleja que le permitía comprender el ser de la colectividad en que la cosa (el crimen) había sido cometida" (p. 327).

En su investigación, comienzan a atarse los cabos. El ingeniero-jefe posee el plano de la gran ciudad, cuyo río está convertido en cloaca y cuyos habitantes son peces-crustáceos en descomposición. La investigación es descrita nue- 
vamente utilizando la técnica positivista, especialmente en la reproducción del habla de la criada del ingeniero-jefe: "Cuand o yo le desperté al señor, por algo sería... El señor enfadó mucho y señorita, toa despeinada... Y yo estaba asustada porque ya sentí que sería algo... No sabe usted qué voz, el pobrecito asustao estaría: que se ponga ingeniero enseguida..." (p. 349).

La investigación prosigue y, al tener acceso al habla de los personajes, por medio del descubrimiento de su lenguaje. Son los enmascarados quienes han despertado en Agustín la concupiscencia del saber, y por lo tanto será por ellos que se inicia la investigación (p. 401). Para ello será necesario, a su vez, que Agustín se despoje de sú máscara de juez: "ser juez y no serlo"era la paradoja que se le había propuesto, pues en su deseo de saber, Agustín se había despojado de su propia máscara la noche de carnaval en que subió las escaleras del casino. Al hacerlo había caído en una especie de complicidad y se había expuesto al tormento del sentimiento de culpa de aquél que recibe al soplo (p. 403).

En el interrogatorio de la criada es donde el autor-narrador enlaza su investigación psico-sociológica y lingüística: “Agustín sentía crecer en el placer del conocimiento según iba captando el mensaje envuelto en su imperfecta jerga, no propiamente dialectal, sino artísticamente deformada para adaptar en lo posible un idioma de otro genio a la peculiaridad sintáctica y flexiva de la subyacente pauta del vernáculo..." (p. 405). Agustín experimenta en este momento, como el autor mismo, el placer del descubrimiento de la relación de complicidad de la víctima (el sereno) con su elevado protect or (el ingeniero-jefe) por medio del estudio de la filología comparada y de la psicología de la domesticidad (p. 406). Estos tres planos superpuestos, cuya base estructural es la elaboración lingüística, son los estratos en que se basa la investigación del autor-narrador-personaje. Esta investigación supond rá la caída; ella llevará al conocimiento de lo prohibido, de las relaciones desenmascaradas del hombre ibérico en su especialidad y con los otros. La investigación del crimen nos paseará por los diversos estratos sociolingüísticos. Ya hemos visto un ejemplo del lenguaje revelador de la psicología de la domesticidad. La mujer del ingeniero y Margarita constituirán el ejemplo de un estrato social más elevado: "Margarita inicia con una gracia nueva... las cabriolas inspiradas... Agustín contempla... una realidad bajo el teatro (máscaras nuevamente).... Aunque los gestos se corresponden fielmente con los aprendidos y aunque el lenguaje de que disponen (puesto que no conocen otro) sea el mismo lenguaje mitificado por la mentira persistente del jugueteo social entre iguales..." (p. 421).

La aproximación a la realidad escondida bajo la máscara llevará a la presentación de esta realidad descubierta bajo la forma de una sucesión de imágenes y descripciones de situaciones anómalas, de un Aquelarre goyesco: a 
pesar de la destrucción del lenguaje y de la intertextualidad, la referencia es clara: "OOh Patria! Miré los muros de la Patria mía..." (p. 456). En este Aquelarre se hace referencia a la verdad escondida bajo las máscaras, bajo la fiesta y bajo el símbolo de la cloaca, o río putrefacto de la gran ciudad. En esta verdad está contenida toda la historia de España, la Santa Tierra Judaica, la Tercera Roma Espiritual, "quizá en la última casa de la Navarra carlista donde se hizo la misa negra y el aquelarre de la bebida del sapo negro y del gato pardo destruidos más allá de los Iconos donde sin embargo brilla la apacible mirada del alto Consuelo divino"(p. 455), la España donde el lumpen proletario debe reproducirse para la continuidad de la clase, "ad mitiendo en la propia carne la posesión de la clase posidente" (p. 459), alusión a la criadita que se deja poseer por el dueño de casa, manifestación de la psicología de la servidumbre, la que materializa el significado del materialismo idealista que el autor Martín-Santos ha intentado comprender, y que se expresa en la frase “Polvo serán más polvo enamorado"(p. 461). Ésta constituye la expresión de uno de los descubrimientos que el autor-narrador-personaje logra; y es que "hay que alzar la espada caliente de la carne mortal para que la carne nueva se rompa de la antigua y se vaya realizando así el dogma de la inmortalidad de la carne que se hace a sí misma, que se autoprod uce según la vieja fórmula de que la vida es la conservación de la forma a pesar y a favor del cambio de la materia..."(p. 27l), descubrimiento que en sí constituye una desobediencia a la que Agustín da "tanto valor" y que naturalmente constituye la desobediencia a los dogmas a los cuales debería haber estado atado, como Demetrios. Por lo tanto al pecado de la carne se añade el pecado contra el espíritu (p. 474). El pecado no puede manifestarse en el lenguaje casto y anquilosado de la tradición. Por ello, la revelación de la verdad deberá hacerse destruyendo el lenguaje, por cuanto en él está toda la historia de esos pueblos privilegiados que la tienen y en los cuales "ella se complace en ver racionalizadas ceremonias del pretérito de un modo absoluto incomprensible" (p. 479). Ante la maldición de ser un pueblo con historia (p. 482) se opone la compensación de la fiesta. Por ello es necesaria la destrucción "de lo inventado (el lenguaje) que expresa todo lo que el hombre es, lo que el hombre odia"(p.493). Es necesario destruir la palabra que ya no dice ni oye porque no sabe y no puede recordar su verdadera significación originaria, la palabra que expresa la fiesta.

Esta destrucción del lenguaje es una destrucción del lenguaje lineal, del lenguaje lógicamente enlazado que expresa un pensamiento anquilosado. Es simple y totalmente la destrucción del lenguaje oficial. Esta destrucción es una destrucción de la sintaxis. Se caracteriza por la falta de puntuación, la repetición obsesiva, reflejo de la actividad de la conciencia del ser-ahí, de una actividad consciente que lucha por desligarse de la máscara del lenguaje que lo 
iguala artificialmente con el otro para la fiesta, y que por lo tanto le quita su propia individualidad, obligándole a repetir los mismos gestos aprendidos, las mismas palabras aprendidas. Esta ruptura de la sintaxis obedece también al uso de la corriente de la conciencia como técnica narrativa. Es el lenguaje el que revela al flujo interior del ser-ahí. Una actividad que consiste en la búsqueda de la autoidentificación, en la cual se demuestra que "el idioma no que la lengua no que lo que llaman lenguaje que la sintaxis ultraperfeccionada que se va hacia el fondo de la cosa y saca su núcleo de esférula brillante. . ."(p. 495), y que cuando se estrella contra el obstáculo puesto por la especialidad del personaje se ve obligada a interrumpir hasta la palabra misma, pues si el ser-ahí se asoma a la verdad, no podrá expresarla con el lenguaje que no le permite "la confirmación de su (mi) pertenencia al mundo de los otros de los duros de los fuertes de los que se atrev..." (p. 47) a referirse a esa realidad oculta prohibida y verdadera utilizando para ello otras veces el latín (p. 462) pero advirtiendo con una parodia que ese uso conducirá: "a la ciudad doliente"... El uso de la intertextualidad, en el cual los textos aludidos o usados han sido alterados para producir el efecto paródico, es otra de las técnicas con que se ha construido y destruido lingüísticamente la novela ( $\mathrm{p}$. 468). Sin embargo, esta destrucción no conduce a una real autoafirmación del yo. El autor-narrador reconoce este hecho y reacciona con un "ya está bien deja la repetición no sirve deja la destrucción busca otra vez la palabra tal vez te ayude..." (p. 497). En esta vuelta a la palabra tal vez se encuentre la posibilidad de transmitir el significado originario, pues el único modo de transmitirlo es por medio de "la sumisión a los que ya lo hicieron antes que nosotros" (p. 506). Con esta ironía del lenguaje termina la novela, pues aunque después de la destrucción se lograra elaborar un nuevo lenguaje, éste solamente podría hacerse en base al anterior o recurriendo a aquél.

Se comprende entonces el deseo de Martín-Santos expresado en el prólogo a su novela de construir una obra al modo de una pieza musical, pues de ese modo se utilizaría la pura sonoridad, los puros significantes desprovistos de significados agotados que ya no significan nada; y por la obra musical se podría construir al modo de una fuga un contrapunto de temas que se repiten y que constituyen los temas de la obra; es decir, la búsqueda del ser-ahí de su ser-con-y-para-otro. Al no poder hacerlo el autor, ha construido su obra dando relevancia a aquellos pequeños elementos de la vida humana que la dotan de significación. De allí la técnica objetivista y detallista de su descripción. De allí el carácter parabólico de Agustín. Ante un personaje disolvente, una lengua igualmente disolvente. Y nos parece justo que el objeto de la búsqueda justifique el método utilizado. 